\title{
New observations on the resistance of coconut cultivars to tropical cyclones in Vanuatu
}

\author{
Jean-Pierre LABOUISSE${ }^{1}$, Tiata SILEYE ${ }^{2}$, Chantal HAMELIN ${ }^{3}$
}

\begin{abstract}
The resistance of coconut palms to violent winds was observed at the Saraoutou research station as cyclone Dani passed over the island of Santo in Vanuatu in January 1999. Mortality caused by felling or uprooting was recorded on 13 Dwarf varieties, 10 Tall varieties and 28 Dwarf x Tall hybrids. The Dwarf palms were generally more susceptible than the Tall palms and hybrids, but substantial differences were also found between varieties in the same group. At 15 years old, the Tacunan Green Dwarf originating from the Philippines proved to be the most resistant Dwarf with $0 \%$ of felled palms compared to $100 \%$ of felled palms for the most susceptible, the Malayan Yellow Dwarf. Of the Tall palms, the Vanuatu Tall proved to be the most resistant with $2 \%$ of felled palms. The varieties originating from the South Pacific or the Philippines also displayed good resistance compared to varieties from Papua New Guinea. Of the hybrids, the Malayan Red Dwarf x Rennell Tall displayed the least resistance. The effect of different factors (morphological characteristics, age) on susceptibility to violent winds is discussed.
\end{abstract}

Key words: Pacific, Vanuatu, coconut, cyclone, genetic diversity, genebank.

\footnotetext{
${ }^{1}$ CIRAD - BIOS, UMR Résistance des Plantes aux Bioagresseurs, TA A-98/IRD, 34394-Montpellier Cedex 5, France; labouisse@cirad.fr (corresponding author)

2 VARTC, PO Box 231, Santo, Vanuatu; tiatas@ vanuatu.com.vu 13CIRAD-BIOS, UMR Développement et Amélioration des Plantes, 34394-Montpellier Cedex 5, France; hamelin@cirad.fr
} 


\section{Introduction}

In the Pacific Ocean, between the Solomon Islands and Fiji, the Vanuatu archipelago stretches over a distance of 850 kilometres between the $13^{\text {th }}$ and $22^{\text {nd }}$ parallels south of the equator. Vanuatu has an equatorial oceanic climate and is periodically subject to tropical cyclones. The Saraoutou coconut research station (now the Vanuatu Agricultural Research and Technical Centre) was founded in 1962 on the island of Espiritu Santo. Since that time, it has been particularly affected by cyclones Wendy in 1972, Gordon (1979), Nigel (1985), Dani and Ella (1999), and Paula and Sose (2001).

The initial work carried out at the station focused on coconut breeding. Thus, from its inception, collections containing varieties of different origins were planted, along with hybrid comparative trials (Calvez et al., 1985; Labouisse et al., 2004; Labouisse et al., 2005). Through the genetic diversity of its collections and the large number of hybrids in trials, the centre is a unique site in the Pacific for observing how different coconut cultivars withstand tropical cyclones. An initial overview was conducted by Marty et al. (1986), but it only distinguished between groups of coconut palms (Dwarfs, Talls, hybrids) without going into detail about the performance of each variety.

We present here observations carried out as tropical cyclone Dani passed over the island of Espiritu Santo from North to South, and struck the collections and trials at the station full on in January 1999. We indicate the differential susceptibility of the varieties and hybrids in relation to violent winds and propose some explanations.

\section{Materials and methods}

The Saraoutou station (longitude $167^{\circ} 12^{\prime} \mathrm{E}$, latitude $15^{\circ} 27^{\prime} \mathrm{S}$ ) is located 11 kilometres north of Luganville on the coast of Espiritu Santo. Its current domain extends over around 500 hectares, on a low terrace along the coast, comprising shallow humus-bearing coral soils, and a limestone plateau enriched with volcanic ash, with deep, fertile soils rich in clay (60-90\%) and organic matter (Bonzon et al., 1991). For this study, all the observations were carried out in coconut plots planted on the latter type of soil, varying in depth from 1.0 to 1.3 metres.

Observations were carried out after cyclone Dani passed through the island of Espiritu Santo from North to South following the $167^{\text {th }}$ eastern meridian (figure 1). On 19 January 1999, the eye of the cyclone passed 30 kilometres to the west of the station with sustained winds reaching 100 knots, i.e. 185 kilometres an hour, with gusts of 120 knots, i.e. 222 kilometres an hour (Tomb, 1999).

Figure 1: Tracking map of cyclone Dani from 13 to 21 January 1999 (position measured every 6 hours)

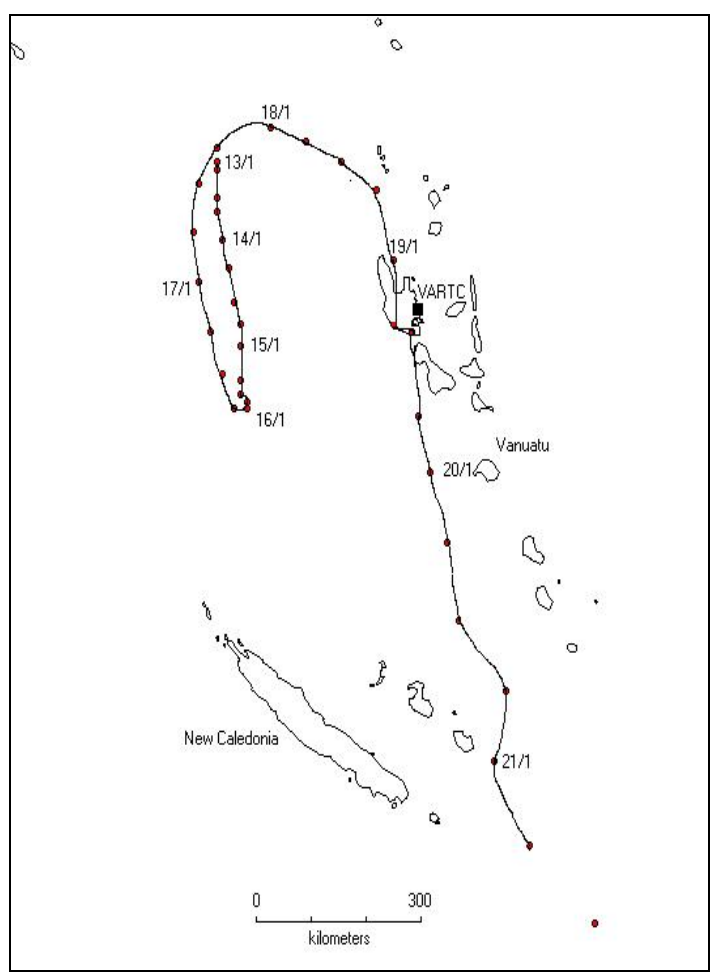

(table 1), and of comparative trials of Dwarf $\mathrm{x}$ Tall hybrids set up under the regional PRAP programme (Pacific Regional Agricultural Programme) from 1982 onwards. The cultivars were in several plots spread over the station and planted at different ages. Exposure of the plots 
to violent winds generated by tropical cyclones varied depending on the environment (proximity to forest curtain or open pasture) and their aspect. We thus classed the plots according to 3 levels of exposure (low, moderate, high). Each plot was pedologically uniform, and contained coconut palms of the same age. Statistical designs had been set up in each plot to observe growth and yield traits, which facilitated a comparison between cultivars in those plots. Table 2 recaps the characteristics of the trials observed.

\section{Results}

\section{Dwarf coconut palms}

In plot (P31), which was highly exposed to gusts of wind, $51.8 \%$ of the 15-year-old Dwarf palms were felled. In all cases, they were snapped off at the root-soil plate level around ten centimetres below ground (figure 2). No stems had been broken above the ground and no palms had been totally uprooted. A small percentage of palms $(4.7 \%)$ only had their stems left leaning by the wind after partial uprooting. Observations showed a wide range of susceptibilities between the Malayan Yellow Dwarf (MYD), the most susceptible with $100 \%$ of felled palms, and the Tacunan Green Dwarf (TACD), with no felled or even leaning palms (figure 3). The Vanuatu Red Dwarf (VRD) was also very resistant with only $3.8 \%$ of felled palms, as was the Samoan Yellow Dwarf (SYD) with $10.6 \%$.

The same varieties were observed in another plot (P51), which was also highly exposed to wind, in 2 blocks planted 4 and 5 years respectively before the passage of the cyclone. In that plot, a majority of palms were left leaning and partially uprooted (19.2\% for the 4-year-old palms and $46.1 \%$ for the 5-year-old palms), and a smaller proportion of totally felled palms $(12.7 \%$ and $24.2 \%$ respectively). Figure 4 shows the percentage of felled and leaning palms depending on the variety in the block of 5-yearold palms. The Niu Leka Dwarf and Tacunan Green Dwarf varieties were the most resistant.

\section{Tall coconut palms}

The Tall coconut palms, which were between 11 and 16 years old and planted in 3 neighbouring plots, were clearly less affected than the Dwarf palms on the whole. Table 3 recaps deaths by felling, along with leaning palms, depending on the variety.

\section{Coconut hybrids}

Observations were carried out in 6 plots containing coconut palms aged 4 to 7 years when the cyclone occurred. In this case, various types of damage were seen with stems broken at different levels (figure 4). The numbers of felled and leaning palms were also recorded (table 4).

\section{Discussion}

Varietal susceptibility between and within groups

After the passage of cyclones Wendy in 1972 and Nigel in 1985, Marty (1986) carried out an inventory of damage seen on coconut palms at the Saraoutou station. He found $32.2 \%$ of Dwarf palms felled by Wendy and $57.2 \%$ by Nigel, as opposed to $5.6 \%$ and $10.4 \%$ respectively for the Tall palms, and $4.6 \%$ and $14.6 \%$ for the hybrids. The observations carried out after the passage of cyclone Dani confirmed the greater susceptibility of the Dwarf group compared to the Tall group, but also substantial variability within those two groups, and depending on age.

Table 1: International codes, names and origins of the coconut varieties 


\begin{tabular}{|c|c|c|c|}
\hline Code & Variety & \multicolumn{2}{|c|}{ Origin } \\
\hline \multicolumn{4}{|l|}{ DWARFS } \\
\hline NLAD & Niu Leka Dwarf & Fiji & \multirow{3}{*}{ SW Pacific Islands } \\
\hline SYD & Samoan Yellow Dwarf & Samoa & \\
\hline VRD & Vanuatu Red Dwarf & Vanuatu & \\
\hline MBD & Madang Brown Dwarf & Papua New Guinea & Papua New Guinea \\
\hline CATD & Catigan Green Dwarf & Philippines & \multirow{3}{*}{ Philippines } \\
\hline PILD & Pilipog Green Dwarf & Philippines & \\
\hline TACD & Tacunan Green Dwarf & Philippines & \\
\hline MRD & Malayan Red Dwarf & Malaysia & \multirow{4}{*}{ South-East Asia } \\
\hline MYD & Malayan Yellow Dwarf & Malaysia & \\
\hline AROD & Aromatic Green Dwarf & Thailand & \\
\hline THD & Thailand Green Dwarf & Thailand & \\
\hline BGD & Brazilian Green Dwarf & Brazil & South America \\
\hline CRD & Cameroon Red Dwarf & Cameroon & West Africa \\
\hline \multicolumn{4}{|l|}{ TALLS } \\
\hline NCT & New Caledonia Tall & New Caledonia & \\
\hline RIT & Rennell Island Tall & Solomon Islands & \\
\hline RTMT & Rotuman Tall & Fiji & \\
\hline TONT & Tonga Tall & Tonga & \\
\hline VTT & Vanuatu Tall & Vanuatu & \\
\hline GPT & Gazelle Peninsula Tall & Papua New Guinea & \multirow{2}{*}{ Papua New Guinea } \\
\hline KKT & Karkar Tall & Papua New Guinea & \\
\hline BAYT & Baybay Tall & Philippines & \multirow{2}{*}{ Philippines } \\
\hline TAGT & Tagnanan Tall & Philippines & \\
\hline MLT & Malayan Tall & Malaysia & South East Asia \\
\hline WAT & West African Tall & Benin & West Africa \\
\hline
\end{tabular}

Table 2: Characteristics of the collections and hybrids trials observed

\begin{tabular}{|l|l|c|c|c|c|}
\hline \multicolumn{1}{|c|}{ Cultivars } & Plot & Age & $\begin{array}{c}\text { Exposure } \\
\text { to strong } \\
\text { winds }\end{array}$ & $\begin{array}{c}\text { Total number } \\
\text { of palms on } \\
\text { the plot }\end{array}$ & $\begin{array}{c}\text { Average } \\
\text { number of } \\
\text { palms per } \\
\text { cultivar }\end{array}$ \\
\hline Dwarfs & P31 & 15 & High & 737 & 56 \\
\hline Dwarfs & P51 (Block 1) & 5 & High & 722 & 55 \\
\hline Dwarfs & P51 (Block 2) & 4 & High & 416 & 42 \\
\hline Talls & P20 & $11-13$ & High & 473 & 94 \\
\hline Talls & P30 & 14 & Medium & 387 & 97 \\
\hline Talls & P40 & $14-16$ & Medium & 953 & 87 \\
\hline Dwarfs x Rennell Island Tall & P105 & 7 & High & 833 & 139 \\
\hline Dwarfs x Tonga Tall & P115 & 6 & Medium & 850 & 142 \\
\hline Dwarfs x Kiribati Tall & P125 & 5 & Medium & 761 & 127 \\
\hline Dwarfs x Rotuman Tall & P104 & 5 & Low & 859 & 143 \\
\hline Dwarfs x Gazelle Tall & P114 & 4 & Medium & 1007 & 144 \\
\hline Dwarfs x Markham Valley Tall & P103 & 4 & Low & 238 & 40 \\
\hline
\end{tabular}

Figure 2: Cyclone damage on Dwarf coconut palms. Block of Malayan Yellow Dwarfs

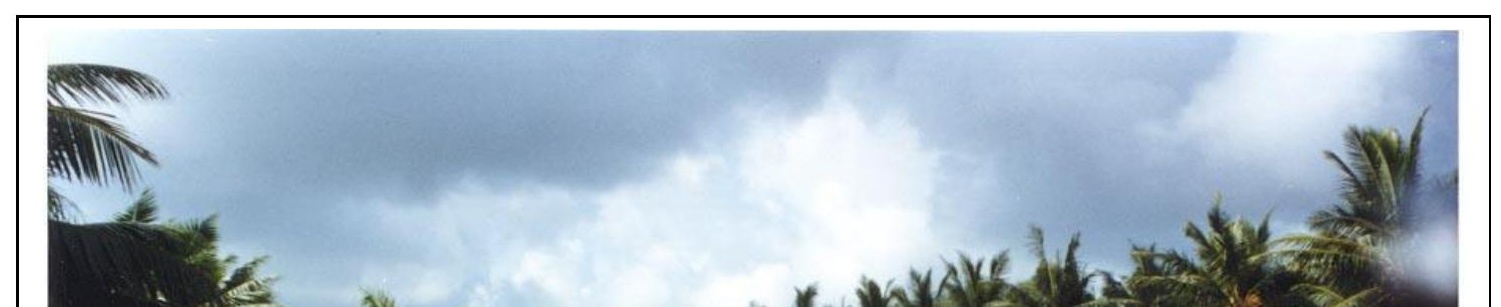


Figure 3: Collection of Dwarf coconuts (15 years old). Percentage of palms felled or left leaning by cyclone Dani depending on the variety

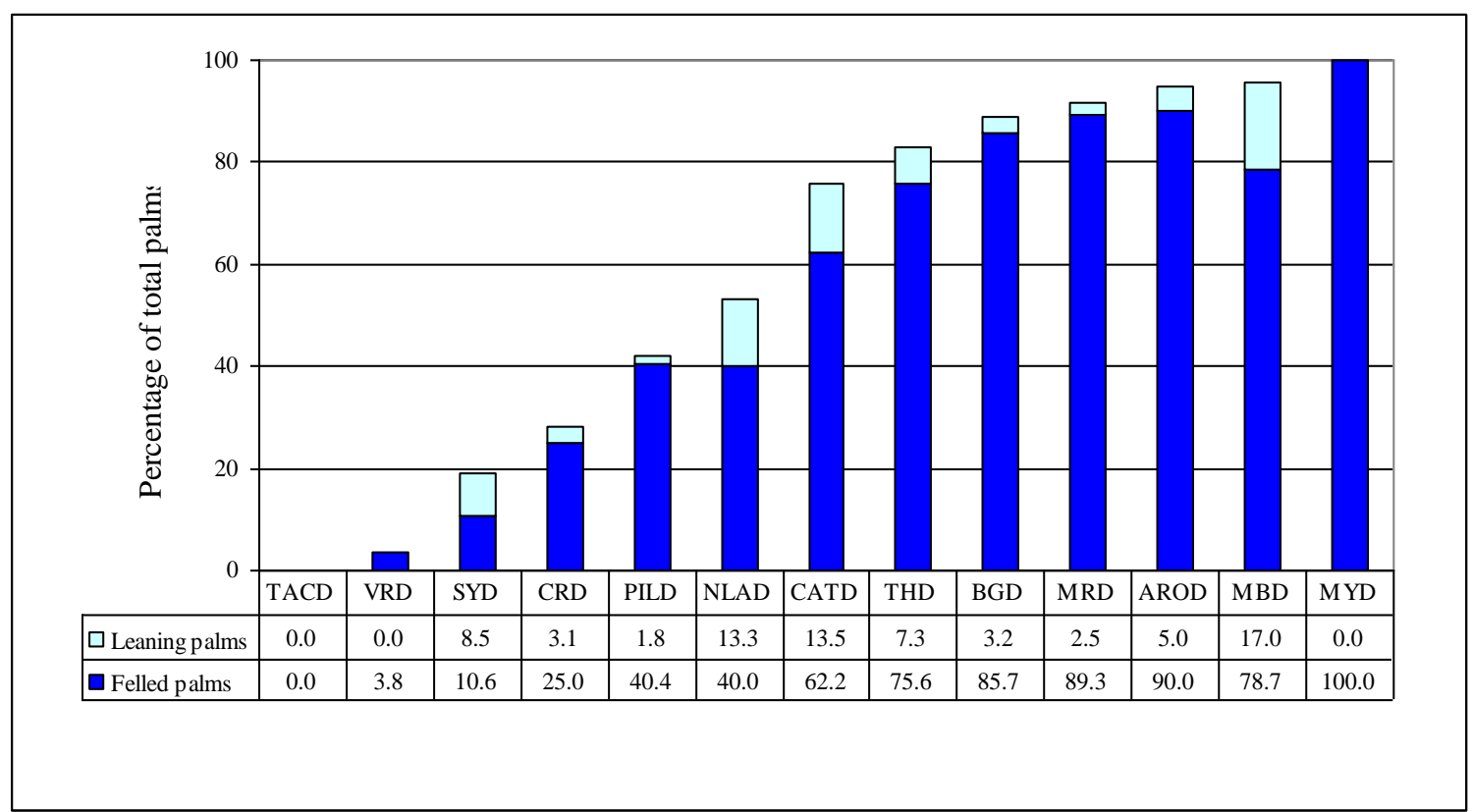

Figure 4: Collection of Dwarf coconuts ( 5 years old). Percentage of palms felled and left leaning by cyclone Dani depending on the variety

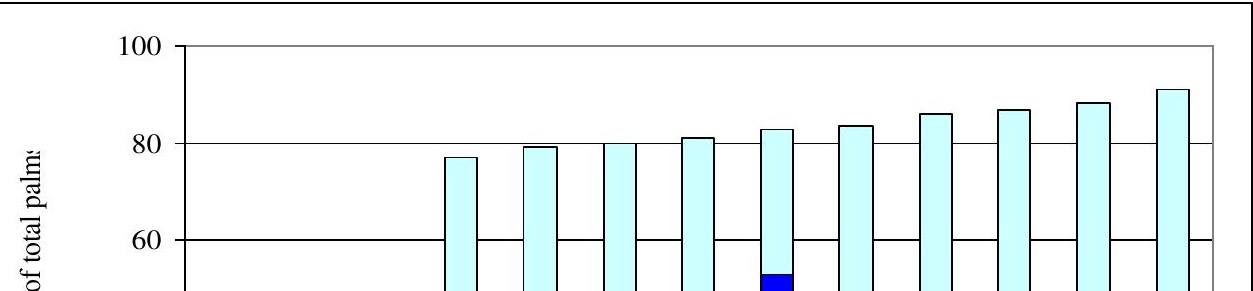


Table 3: Collection of Tall coconuts (11-16 years old). Percentage of palms felled or left leaning by cyclone Dani depending on the variety. The exposure to winds is high for plot P20 and medium for plots P30 and P40

\begin{tabular}{|c|c|c|c|c|}
\hline Origin & Variety Code & Plot & $\begin{array}{l}\text { Percentage of } \\
\text { felled palms }\end{array}$ & $\begin{array}{l}\text { Percentage of } \\
\text { leaning palms }\end{array}$ \\
\hline \multirow{15}{*}{ SW Pacific Islands } & NCT & $\mathrm{P} 20$ & 2.7 & 0.9 \\
\hline & RIT & P30 & 1.0 & 3.0 \\
\hline & RTMT & P30 & 0.0 & 0.0 \\
\hline & TONT & P40 & 6.1 & 8.2 \\
\hline & VTT (all populations merged) & & 2.0 & 0.9 \\
\hline & VTT01 (Surunda) & $\mathrm{P} 40$ & 0.0 & 0.0 \\
\hline & VTT05 (Bulldoz) & P40 & 0.0 & 0.0 \\
\hline & VTT06 (Port Olry) & $\mathrm{P} 40$ & 3.1 & 0.0 \\
\hline & VTT07 (Tanna1) & $\mathrm{P} 40$ & 0.0 & 0.0 \\
\hline & VTT08 (Torres) & $\mathrm{P} 20$ & 0.0 & 0.0 \\
\hline & VTT09 (Tanna2) & $\mathrm{P} 20$ & 7.3 & 1.8 \\
\hline & VTT10 (Banks) & $\mathrm{P} 20$ & 1.8 & 0.0 \\
\hline & VTT GC2 (Improved) & $\mathrm{P} 40$ & 0.0 & 0.0 \\
\hline & VTT Matevulu (Improved) & $\mathrm{P} 20$ & 2.6 & 4.3 \\
\hline & Vanuatu Red Dwarf x Vanuatu Tall & $\mathrm{P} 20$ & 2.2 & 4.3 \\
\hline \multirow{2}{*}{ Papua New Guinea } & KKT & P30 & 20.4 & 12.2 \\
\hline & GPT & P30 & 33.0 & 12.5 \\
\hline \multirow{2}{*}{ Philippines } & BAYT & $\mathrm{P} 40$ & 3.1 & 2.1 \\
\hline & TAGT & $\mathrm{P} 40$ & 7.7 & 3.6 \\
\hline South East Asia & MLT & $\mathrm{P} 40$ & 4.1 & 1.0 \\
\hline West Africa & WAT & $\mathrm{P} 40$ & 33.3 & 0.0 \\
\hline
\end{tabular}

Table 4: Coconut hybrids. Percentage of palms felled or left leaning by cyclone Dani depending on the cultivar 


\begin{tabular}{|c|c|c|c|c|}
\hline Hybrids & $\begin{array}{l}\text { Exposure to } \\
\text { winds }\end{array}$ & Age & $\begin{array}{c}\text { Percentage of felled } \\
\text { palms }\end{array}$ & $\begin{array}{c}\text { Percentage of leaning } \\
\text { palms }\end{array}$ \\
\hline Dwarfs x Rennell Tall & High & 7 & & \\
\hline BGDxRIT & & & 3.5 & 22.5 \\
\hline CRDxRIT & & & 6.8 & 11.3 \\
\hline MBDxRIT & & & 7.0 & 23.1 \\
\hline MYDxRIT & & & 23.1 & 17.9 \\
\hline MRDxRIT (C) & & & 9.9 & 11.4 \\
\hline $\operatorname{VRDxVTT}(\mathrm{C})$ & & & 5.0 & 2.9 \\
\hline Dwarfs x Tonga Tall & Medium & 6 & & \\
\hline MRDxTONT & & & 13.8 & 10.3 \\
\hline MYDxTONT & & & 6.3 & 7.0 \\
\hline NLADx TONT & & & 1.3 & 3.2 \\
\hline SYDxTONT & & & 0.8 & 9.8 \\
\hline MRDxRIT (C) & & & 19.4 & 14.4 \\
\hline VRDxVTT (C) & & & 15.4 & 5.6 \\
\hline Dwarfs x Kiribati Tall & Medium & 5 & & \\
\hline BGDxKIT & & & 5.8 & 6.6 \\
\hline BGDxRGT & & & 2.9 & 3.6 \\
\hline MBDxKIT & & & 0.0 & 1.4 \\
\hline MRDxKIT & & & 4.9 & 2.1 \\
\hline MYDxKIT & & & 4.8 & 4.8 \\
\hline VRDxVTT (C) & & & 12.9 & 2.1 \\
\hline Dwarfs x Rotuman Tall & Low & 5 & & \\
\hline CRDxRTMT & & & 0.7 & 0.0 \\
\hline MBDxRTMT & & & 0.7 & 3.5 \\
\hline MYDxRTMT & & & 2.1 & 1.4 \\
\hline MRDxRTMT & & & 0.7 & 2.0 \\
\hline MRDxRIT (C) & & & 10.1 & 3.6 \\
\hline VRDxVTT (C) & & & 4.9 & 0.0 \\
\hline Dwarfs x Gazelle Peninsula Tall & Medium & 4 & & \\
\hline BGDxGPT & & & 2.8 & 6.3 \\
\hline CRDxGPT & & & 6.3 & 3.5 \\
\hline MBDxGPT & & & 0.7 & 6.3 \\
\hline MRDxGPT & & & 4.2 & 3.5 \\
\hline MYDxGPT & & & 9.7 & 6.9 \\
\hline MRDxRIT (C) & & & 12.5 & 6.3 \\
\hline $\operatorname{VRDxVTT}(\mathrm{C})$ & & & 8.3 & 3.5 \\
\hline Dwarfs x Markham Valley Tall & Low & 4 & & \\
\hline CRDxMVT & & & 4.17 & 0 \\
\hline MBDxMVT & & & 0 & 2.86 \\
\hline MRDxMVT & & & 2.13 & 0 \\
\hline MYDxMVT & & & 5.56 & 0 \\
\hline MRDxRIT & & & 18.75 & 2.08 \\
\hline VRDxVTT & & & 2.08 & 0 \\
\hline
\end{tabular}

Under the conditions of our study, the Tacunan Green Dwarf (TACD) displayed noteworthy resistance to violent winds, a trait already found in the Philippines, its country of origin (G. Santos, personal communication). That
Dwarf palm has a broader stem at the base and a moderate height, which might explain a large share of its resistance. In Jamaica, Johnson et al. 
(1994) found a simple relation ${ }^{4}$ between two parameters, the diameter of the bole and stem height, and the death rate caused by a cyclone in hybrids between the Malayan Red Dwarf and Tall palms. In Vanuatu, we had stem measurements (stem height, stem circumference $0.20 \mathrm{~m}$ from the ground) taken 4 years before the passage of the cyclone for the same collection of Dwarf palms. If those 2 parameters were represented on a simple graph (figure 5), TACD stood out from the other Dwarf coconut palms studied, with a stem height: bole girth ratio $(\mathrm{S}: \mathrm{B})$ of 2.56. The other varieties, apart from the Niu Leka Dwarf, had variable measurements, with a $\mathrm{S}: \mathrm{B}$ ratio between 3.2 and 4.38 , but those parameters alone did not explain the great differences in susceptibility found between those varieties. Lastly, the Niu Leka was a very particular case $(S: B=1.69)$. It is a very slowgrowing palm with a short, broad stem, and a compact crown of fairly rigid fronds with broad leaflets providing a good hold for the wind.

In the case of the Tall palms, the different Vanuatu Tall populations were among the most resistant varieties with, all populations combined, $2 \%$ of felled palms and under $1 \%$ of leaning palms. The varieties from the Pacific Islands (New Caledonia, Rotuma, Rennell, and, to a lesser degree, Tonga) also resisted well, as did those from the Philippines (Baybay Tall and Tagnanan Tall). The Tall palms from Papua New Guinea displayed little resistance, with up to 33\% of felled palms for the Gazelle Peninsula Tall. The West African Tall also displayed little resistance, but it had already been weakened by severe Phytophthora palmivora attacks.

For the hybrids, significant differences were also found between genotypes in the plantings set up between 4 and 7 years before the cyclone occurred. At those ages, the MRD x RIT hybrid, which is widespread in the Pacific due to its high yields, seemed to be most susceptible but it also bore the heaviest nut load.

${ }^{4}$ Mortality $=0.613-0.552 x+0.264 \mathrm{y}($ where $\mathrm{x}=$ bole girth and $\mathrm{y}=$ stem height, in metres)

\section{Effect of age}

The coconut palms under 4 years old suffered little damage apart from a few torn fronds. The 4 to 5 -year-old Dwarf palms were partially uprooted, causing the stems to lean. With age, the density of the root system network and rooting depth increase. Under the conditions in our study, the 15-year-old Dwarf palms were well anchored in the deep soil. Even partial uprooting was therefore more difficult and breakage occurred at the point where the balance between the forces exerted by the wind and the plant's forces of resistance was broken, i.e. in the absence of a bole, at the basal extremity of the stem.

In the case of hybrids, we had two cultivars, VRDxVTT and MRDxRIT, present as controls in the plots planted at different ages. The data in table 4 show that the damage caused by violent winds started to be significant as soon as the coconut palms reached 4 years, was maximum at 5 and 6 years and seemed to decrease slightly from 7 years onwards. Coconut hybrids have a bole which strengthens the stem base. Consequently, for these young palms, we found either partial uprooting or stem breakage above the bole.

In the case of the Tall palms, which were over 11 years old and had a bole and welldeveloped root system, resistance to violent winds was very good, except for the varieties 
Figure 5: Cyclone damage on coconut hybrids. Block of Dwarfs $x$ Rennell Island Tall hybrids

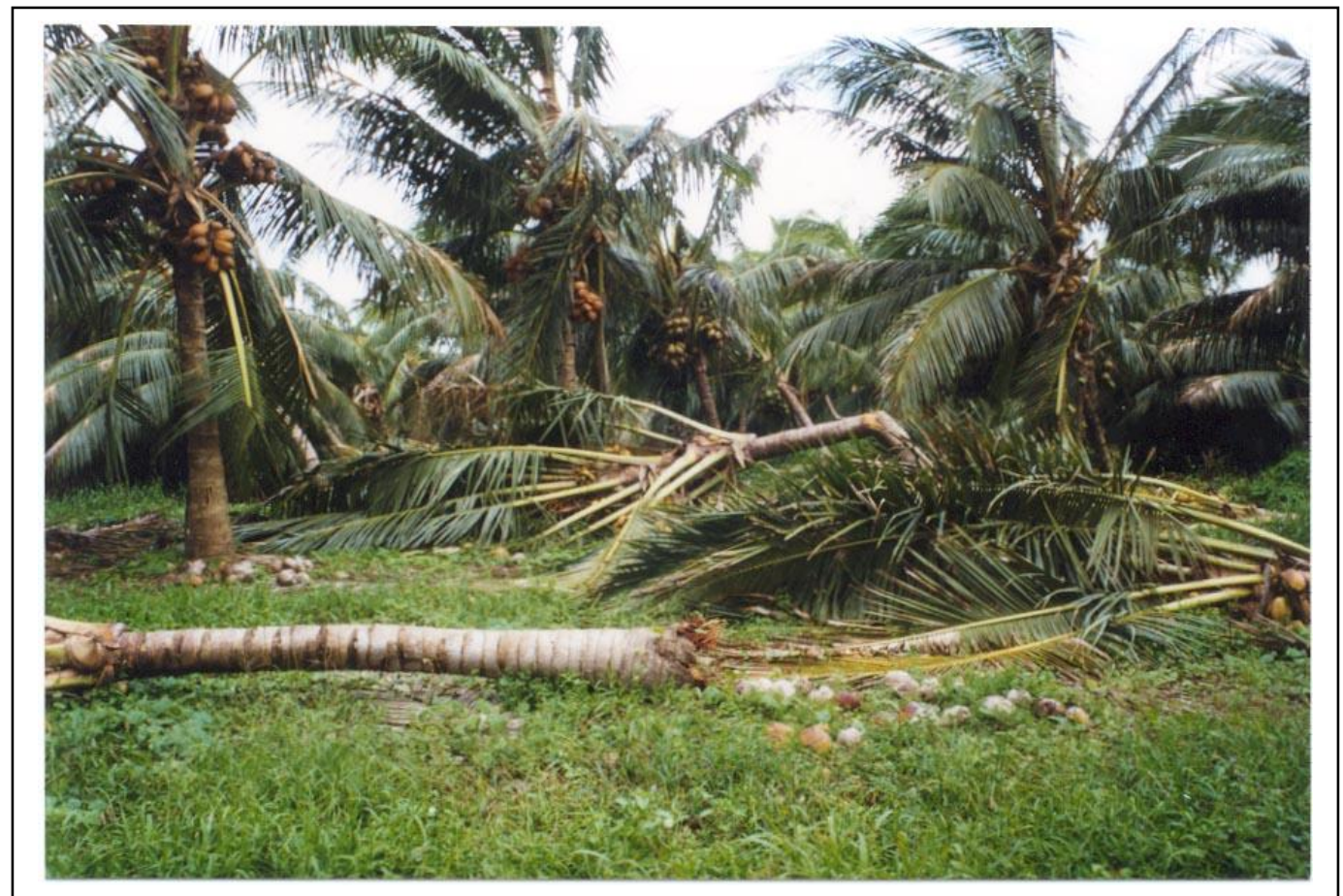

Figure 6: Dwarf coconut measurements with $x$-axis, stem circumference $20 \mathrm{~cm}$ from the ground (in metres) and $y$-axis, stem height

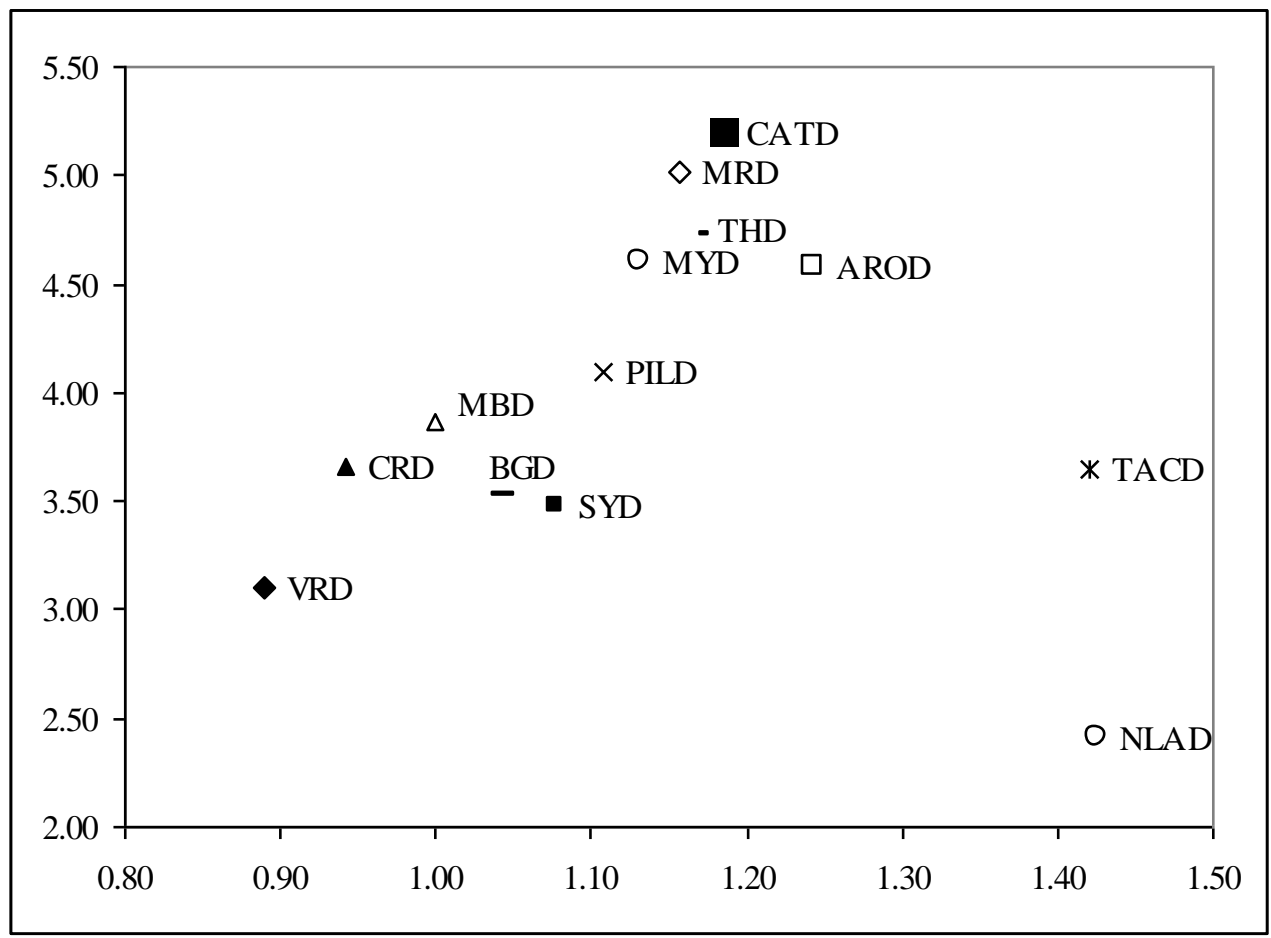


from Papua New Guinea. After the passage of cyclone Nigel in 1985, Marty (1986) found relatively severe damage on Vanuatu Tall palms over 8 years old, with $12 \%$ of felled palms. However, those plantations had been set up on shallow coral soil and the palms had toppled over due to a superficial root system.

In the absence of any detailed individual morphological measurements, an analysis of factors affecting how coconut palms fare in relation to violent winds can barely be taken any further.

\section{Conclusion}

The passage of cyclone Dani at the Saraoutou station provided the opportunity of assessing the susceptibility of different coconut varieties in a particularly uniform environment. For mature palms, it was confirmed that Dwarf palms were clearly more susceptible than Tall palms, mainly due to the lack of a bole at the base of the stem. Differences in susceptibility between Dwarf palms were very clear and depended on the morphological characteristics of the varieties, such as stem base width, stem height and crown characteristics (weight and volume of fronds and fruits). The physical characteristics of the wood (strength, elasticity), which were not measured in this study, can also probably be added.

Lastly, it can be noted that natural selection seems to have played a role in the acquisition of a variety's ability to resist violent winds. Dwarf and Tall varieties, which originate from the South Pacific and the Philippines, where cyclones are frequent, seemed on average to be clearly more resistant than varieties from Papua New Guinea, Southeast Asia and West Africa.

\section{Acknowledgment}

We thank VARTC and Vanuatu Government for the continuous support to the coconut breeding programme, and coconut division staff, especially M. Jean-Pierre Tabiusu. We thank Peter Biggins (CIRAD) for the translation of this article.

\section{References}

Bonzon, B., Podwojewski, P., Bourdon, E., L'Huillier, L. and de Montpezat, P. (1991). Recherches préliminaires pour le développement de la culture du cocotier sur les petits archipels du Pacifique Sud. 1- Adaptation à l'espèce des tests de fertilité sur vases de végétation, 2 Identification des sols sous cocoteraies présentant des carences difficiles à éliminer. Problématique de la mise en valeur de tels sols. Nouméa, NouvelleCalédonie, Institut Français pour la Recherche Scientifique pour le Développement en Coopération (ORSTOM): 275 p.

Calvez, C.-H., Julia, J.-F. and de Nucé, M. (1985). L'amélioration du cocotier au Vanuatu et son intérêt pour la région du Pacifique: rôle de la station de Saraoutou/Improvement of coconut in Vanuatu and its importance for the Pacific region: role of the Saraoutou Station. Oléagineux 40(10): 477-490.

Johnston, C. F., Fielding, W. J. and Been, B. (1994). Hurricane damage to different coconut varieties. Trop. Agric. (Trinidad) 71(3): 239-242.

Labouisse, J.-P., Sileye, T., Morin, J.-P., Baudouin, L., Bourdeix, R. and Rouzière, A. (2004). Coconut (Cocos nucifera L.) genetic improvement in Vanuatu: overview of research achievements from 1962 to 2002. Part 1: Improvement of the Vanuatu Tall by mass selection. OCL Oléagineux, Corps Gras, Lipides 11(4-5): 354-361.

Labouisse, J.-P., Sileye, T., Morin, J.-P., Baudouin, L., Bourdeix, R. and Rouzière, A. (2005). Coconut (Cocos nucifera L.) genetic improvement in Vanuatu: overview of research achievements from 1962 to 2002. Part 2: Improvement of the Vanuatu Tall by hybridization. $O C L$ Oléagineux, Corps Gras, Lipides 12(2): 170-179. 
Marty, G., Le Guen, V. and Fournial, T. (1986). Effets des dépressions cycloniques sur les plantations de cocotiers au Vanuatu. Oléagineux 41(2): 63-69.
Tomb (1999). Track of tropical cyclone 11P (Dani). [Online]. Available at http://hcane.tripod.com/trpdta/11p.html. Verified 22 March 2007, Hurricane Alley. Hosted by Tripod. 